\title{
Central line-associated bloodstream infections in the neonatal intensive care unit
}

\author{
Woo Ryoung Lee, MD, PhD \\ Department of Pediatrics, Soonchunhyang University Seoul Hospital, Soonchunhyang University College of Medicine, Seoul, Korea
}

Over the past several decades, Korea has achieved a remarkable progress in the medical field. The Korean health system provides access to well-developed health care services. In the midst of this rapid expansion of technology and knowledge, there is a growing awareness of the importance of high quality of care.

Quality health care is important in all aspects of clinical practice, but particularly in criticallyill patients treated in intensive care units because it significantly impacts patient mortality and long-term prognosis. In this context, improvements in the quality of the neonatal intensive care units require priority.

The World Health Organization defines quality of care as the extent to which health care services provided to individuals and patient populations improve the desired health outcomes. The main elements are safety, effectiveness, timeliness, efficiency, equitability and peoplecenteredness. ${ }^{1)}$ Among them, patient safety is a major concern globally in the developing as well as developed and high-income countries. ${ }^{2)}$

Preventing healthcare-associated infections is a core element of improving patient safety. Healthcare-associated infections include central-line associated bloodstream infection (CLABSI), ventilator-associated pneumonia, catheter-associated urinary tract infection, and surgical site infection. ${ }^{3)}$ To reduce healthcare-associated infections and improve patient safety, healthcare centers implement evidence-based care and checklists. The Korean National Healthcare-Associated Infections Surveillance System monitors healthcare-associated infection rates as in other countries. ${ }^{4,5)}$

CLABSIs are among the most common healthcare-associated infections in the neonatal intensive care unit. ${ }^{6}$ However, the definition of CLABSIs in newborn differs from that of any other age group. ${ }^{7)}$ In addition to the issue on definitions, there are special considerations that healthcare centers should pay attention to when implementing preventive strategies.

The article about CLABSIs in neonates ${ }^{7)}$ provides the definition, etiology, and pathogenesis of bloodstream infections as well as strategies for preventing them. The authors defined 2 different types of bloodstream infections that were associated with central venous catheters: catheter-related bloodstream infection and CLABSIs. However, a definition specific to neonates is still needed and requires further research. Regarding preventive strategies, adequate patientto-staff ratios should be guaranteed as part of the government's continued attention and support. Medical personnel should be educated and trained accordingly.

In conclusion, the prevention and management of CLABSIs in the neonatal intensive care unit is very important. Thus, medical personnel should clearly understand the pathogenesis of CLABSIs and become educated and trained on the various preventive strategies, while the government should expand its support accordingly.
Corresponding author: Woo Ryoung Lee, MD, PhD Department of Pediatrics, Soonchunhyang University Seoul Hospital, Soonchunhyang University College of Medicine, 59, Daesagwanro, Yongsangu, Seoul 04401, Korea

Tel: +82-2-709-9338

Fax: +82-2-794-5471

E-mail: neolee@schmc.ac.kr

https://orcid.org/0000-0002-1758-2444

Received: 19 March, 2019

Revised: 15 July, 2019

Accepted: 17 July, 2019
Copyright $(\subset 2019$ by The Korean Pediatric Society

This is an open-access article distributed under the terms of the Creative Commons Attribution NonCommercial License (http://creativecommons.org/ licenses/by-nc/4.0/n which permits unrestricted noncommercial use, distribution, and reproduction in any medium, provided the original work is properly cited. 


\section{Conflicts of interest}

No potential conflict of interest relevant to this article was reported.

\section{References}

1. World Health Organization. Standards for improving quality of maternal and newborn care in health facilities [Internet]. Geneva (Switzerland): World Health Organization; 2016 [cited 2019 Mar 15]. Available from: https://www.who.int/maternal_child_adolescent/documents/ improving-maternal-newborn-care-quality/en/.

2. World Health Organization. Patient safety. Making health care safer [Internet]. Geneva (Switzerland): World Health Organization; 2017 [cited 2019 Mar 15]. Available from: https://www.who.int/patientsafety/ publications/patient-safety-making-health-care-safer/en/.
3. Centers for Disease Control and Prevention. Healthcare-associated infections. [Internet]. Atlanta (GA): Centers for Disease Control and Prevention; 2016 [cited 2019 Mar 15]. Available from: https://www. cdc.gov/hai/index.html.

4. Kwak YG, Choi YH, Choi JY, Yoo HM, Lee SO, Kim HB, et al. Korean national healthcare-associated infections surveillance system, intensive care unit module report: summary of data from july 2015 through June 2016. Korean J Healthc Assoc Infect Control Prev 2017;22:9-20.

5. Centers for Disease Control and Prevention. National and state healthcare associated infections: progress report [Internet]. Atlanta (GA): Centers for Disease Control and Prevention; 2016 [cited 2019 Mar 15]. Available from: http://www.cdc.gov/HAI/pdfs/progress-report/haiprogress-report.pdf.

6. Mobley RE, Bizzarro MJ. Central line-associated bloodstream infections in the NICU: Successes and controversies in the quest for zero. Semin Perinatol 2017;41:166-74.

7. Cho HJ, Cho HK. Central line-associated bloodstream infections in neonates. Korean J Pediatr 2019;62:79-84. 